\section{Acta 3iologica Gibirica}

Journal of Biology

Founded in 2015
Altai State University

www.asu.ru

ISSN 2412-1908

\title{
Fauna of bees (Hymenoptera, Apoidea: Apiformes) of the relict lime forest of the mountain Shoria
}

\author{
D.A. Sidorov, S.L. Luzyanin \\ Kemerovo State University, Krasnaya str. 6, Kemerovo 650000, Russia. \\ E-mail: raddimus@yandex.ru
}

\begin{abstract}
Intermediate results of the study of the fauna of bees in the relict lime forest of Mountain Shoria (Kemerovo region) are given. 74 species of bees from 15 genera and 6 families were recorded, 8 species of them are newly registered in Kemerovo region. The family Apidae is dominating in the number of species (at the expense of bumblebees) and the family Colletidae (without taking into account the bumblebees) - in the number of exemplars, because of the numerous genus Hylaeus. The highest number of species belongs to the genera Bombus (15) and Andrena (14). The population of bees varies significantly during the summer season. Most of the recorded species of bees has very wide ranges of distribution, endemics and new taxa were not discovered.
\end{abstract}

Key words: biodiversity, nemoral relicts, new records, Siberia

\section{Фауна пчел (Hymenoptera, Apoidea: Apiformes) реликтового липового острова Горной Шории}

\author{
Д.А. Сидоров, С.Л. Лузянин \\ Кемеровский государственный университет, ул. Красная 6, Кемерово 650000 Россия. \\ E-mail: raddimus@yandex.ru
}

\begin{abstract}
Подведены промежуточные итоги изучения фауны пчел реликтовых лесов с участием липы сибирской, расположенных в Горной Шории (Кемеровская область). Обнаружено 74 вида пчел из 15 родов и 6 семейств, из которых 8 видов впервые указаны для Кемеровской области. По числу видов преобладает семейство Аріdaе (за счёт шмелей), по числу особей (без учёта шмелей) - Colletidae (род Hylaeus). Наиболее богаты видами роды Bотbus (15) и Andrena (14). Население пчел существенно меняется в ходе летнего сезона. Большая часть обнаруженных видов пчел имеет обширные ареалы, эндемики и новые виды выявлены не были.
\end{abstract}

Ключевые слова: биоразнообразие, неморальные реликты, новые находки, Сибирь

\section{Введение}

На территории Горной Шории (Кемеровская область) расположен один из крупнейших массивов широколиственного леса в Сибири - так называемый липовый остров, площадью около 110 км² (Amelin, Blyakharchuk, 2016). Флору и растительность этого реликтового фитоценоза к настоящему времени можно считать хорошо изученными. Установлено, что ядро флоры Липового острова составляет 30 неморальных видов 
Sidorov, D.A. Luzyanin, S.L. Fauna of bees (Hymenoptera, Apoidea).... Acta Biologica Sibirica, 2018, 4(1), 24-32

растений. В то же время, энтомофауна липового острова остаётся почти неизученной (Krapivkina, 2009). Комплексное изучение биоразнообразия реликтовых сообществ представляет большой интерес с точки зрения познания развития экосистем Южной Сибири в современную межледниковую эпоху.

Пчелы - процветающая группа перепончатокрылых насекомых (Hymenoptera), насчитывающая в мировой фауне более 17 тысяч видов, 443 рода и 7 семейств, а на территории России - 1216 видов из 66 родов и 6 семейств (Michener, 2007; Antropov et al., 2017). Изученность фауны пчел в Алтае-Саянской горной стране и на сопредельных территориях Сибири остаётся недостаточной. К настоящему времени опубликован ряд обзорных статей по фауне пчел крупных регионов Сибири (Proshchalykin, Lelej, 2014; Astafurova, Proshchalykin, 2015, 2017; Proshchalykin, Kuhlmann, 2015; Proshchalykin, Dathe, 2016; Proshchalykin et al., 2016; Sidorov, Proshchalykin, 2017; Sidorov et al., 2017), однако локальные фауны пчел остаются исследованными весьма поверхностно, что затрудняет проведение сравнительно-фаунистических исследований и анализ механизмов экологической дифференциации отдельных таксонов пчел. Статья подводит итоги первого специального фаунистического исследования пчел в реликтовых экосистемах Алтае-Саянской горной страны.

\section{Материал и методы исследований}

Сбор материала был проведён на территории Федерального памятника природы «Липовый остров» (Кемеровская область, Новокузнецкий район, 7 км восточнее п. Кузедеево, 53 19' с. ш., 87 18' в. д.). Ввиду существенных различий в фенологии, экологии и биологии, а также степени изученности, сбор и изучение шмелей (Bombus Latreille, 1802) проводили отдельно от других групп диких пчел. Медоносных пчел (Apis теllifera Linnaeus, 1758) не собирали и не учитывали. Общий объём собранной и изученной коллекции составил 591 экземпляр шмелей и 1061 экземпляр других пчел. Для достижения максимальной полноты выявления локальной фауны пчел сбор материала проводили в несколько этапов: в 2016 (22-25 мая, 67 экземпляров; 1-4 июля, 149 экз.) и 2017 году (3-13 июля, 625 экз. и 17-18 августа, 225 экз.). Собранный материал хранится в коллекции кафедры экологии и природопользования Кемеровского государственного университета, часть материала по семействам Halictidae и Megachilidae передана для изучения и хранения в Зоологический институт РАН (г. Санкт-Петербург) и Новосибирский государственный университет.

Пчел собирали в различных биотопах, для которых приняты условные обозначения: «поляна» - разнотравнозлаковый суходольный луг; «дорога» - высокотравный лесной луг; «ПЛ1» - липняк крупнотравный, разреженный; «ПЛ2» - липняк папоротниково-крупнотравный. Всех замеченных в ходе движения по маршруту пчел отлавливали энтомологическим сачком или пинцетом. Кроме того, в исследованных биотопах были установлены ловушки Мерике. Для обозначения сборщиков приняты сокращения: СД - Д.А. Сидоров, ЯС - С.Н. Яковлева, ЛС С.Л. Лузянин. Самки-основательницы шмелей обозначены $q$ (q), рабочие особи - $+(w)$.

Пчелы рода Bombus (шмели) определены С.Л. Лузяниным, семейства Halictidae - Ю.В. Астафуровой (Зоологический институт РАН, Санкт-Петербург), семейства Megachilidae - А.М. Бывальцевым (Новосибирский государственный университет, Новосибирск), остальные пчелы - Д.А. Сидоровым.

Общая система пчел и названия видов приводятся в соответствии с «Аннотированным каталогом перепончатокрылых насекомых России» (Antropov et al., 2017). Для ареалогического анализа принята упрощённая схема К.Б. Городкова (Gorodkov, 1984). Типы ареалов выделены на основе сведений о распространении, взятых из «Аннотированного каталога перепончатокрылых насекомых России» (Antropov et al., 2017). Подробные сведения о распространении не приводятся, так как они имеются в указанном каталоге.

\section{Результаты и обсуждение}

В составе локальной фауны пчел Липового острова обнаружено 74 вида, относящихся к 15 родам и 6 семействам. К настоящему времени остаётся не определённым материал по роду Nomada Scopoli, 1770 (не менее 2х видов). Кроме того, исследованием не был охвачен ранневесенний фенологический сегмент фауны пчел. Таким образом, на территории Липового острова ожидается обнаружение ещё около 10 видов пчел.

Большая часть материала, собранного в 2016 году, опубликована ранее (Sidorov et al., 2016), данные об оставшейся части материала приведены ниже, с указанием 2016 года в дате сбора. Интенсивный сбор материала в 2017 году позволил расширить список видов пчел Липового острова 38 до 74. Кроме того, найдено 8 видов, ранее не указанных для Кемеровской области (обозначены *).

\section{Семейство Colletidae}

Hylaeus (Dentigera) brevicornis Nylander, 1852

Тип ареала: евро-сибирский.

Материал: дорога, 12.VII, ЛС, СД - 2 о; поляна, 17-18.VIII, СД, ЯС - 1 ․

Hylaeus (Dentigera) gredleri Föerster, 1871*

Тип ареала: евро-сибирский. 
Sidorov, D.A. Luzyanin, S.L. Fauna of bees (Hymenoptera, Apoidea).... Acta Biologica Sibirica, 2018, 4(1), 24-32

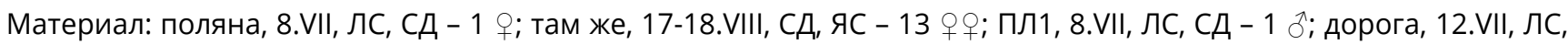
СД - 5 우.

\section{Hylaeus (Hylaeus) annulatus (Linnaeus, 1758)}

Тип ареала: голарктический.

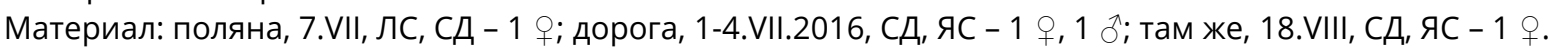

\section{Hylaeus (Hylaeus) cardioscapus Cockerell, 1924}

Тип ареала: трансевразиатский.

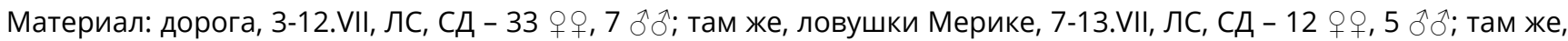

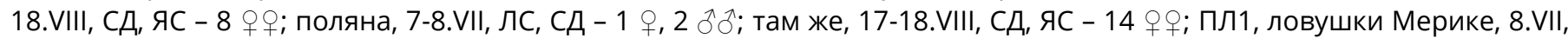
ЛС, СД - 1 о; ПЛ2, ловушки Мерике, 8-9.VII, ЛС, СД - 1 о.

\section{Hylaeus (Hylaeus) gracilicornis (Morawitz, 1867)}

Тип ареала: трансевразиатский.

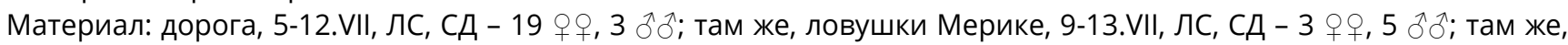
18.VIII, СД, ЯС - 3 фо; ПЛ2, ловушки Мерике, 8-9.VII, ЛС, СД - 2 фо; ПЛ1, ловушки Мерике, 12.VII, ЛС, СД - 3 о; поляна, 17-18.VIII, СД, ЯС - 8 우.

\section{Hylaeus (Hylaeus) paulus Bridwell, 1919*}

Тип ареала: трансевразиатский.

Материал: дорога, 12.VII, ЛС, СД- 6 o+ , 1 §.

\section{Hylaeus (Lambdopsis) rinki (Gorski, 1852)}

Тип ареала: трансевразиатский.

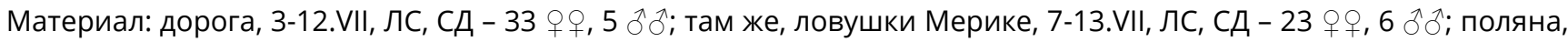

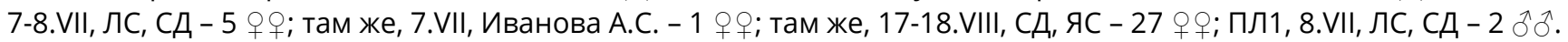

\section{Hylaeus (Patagiata) nigrocuneatus Cockerell, 1924}

Тип ареала: сибиро-дальневосточный.

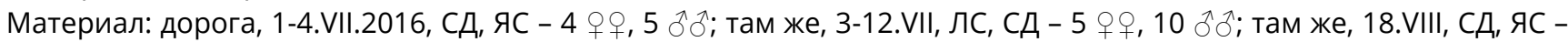

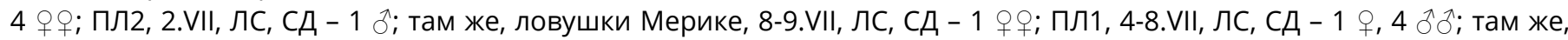
ловушки Мерике, 9-12.VII, ЛС, СД- 3 우, 3 ふึぇં; поляна, 17-18.VIII, СД, ЯС - 10 우.

\section{Hylaeus (Prosopis) confusus Nylander, 1852}

Тип ареала: трансевразиатский.

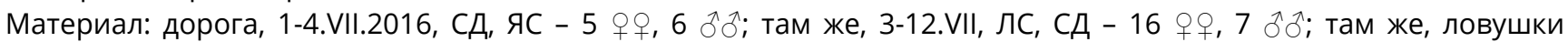

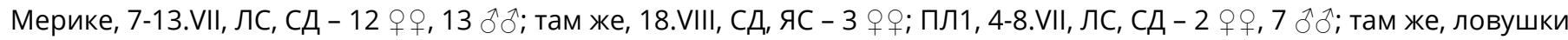

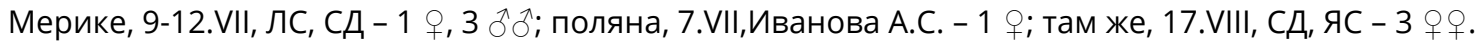

\section{Семейство Andrenidae}

\section{Andrena (Andrena) fucata Smith, 1847}

Тип ареала: евро-сибирский.

Материал: дорога, 3-12.VII, ЛС, СД - 27 कө; ПЛ1, 4.VII, ЛС, СД - 3 фо; ПЛ2, 4-7.VII, Фазилов Б.Б. - 2 ㅇ; там же, 78.VII, Муминова А.Г. - 2 о⿱ ; поляна, 7-8.VII, ЛС, СД - 14 от ; там же, 7-13.VII, Антонова М.В., Вейс В.А., Груздева Т.В., Дернова Е.В., Краснокуцкая А.Д., Лозовой П.А.,Сорокин Н.С., Старчикова Д.А., Турушева А.С., Фазилов Б.Б. - 28 우, 1 o.

\section{Andrena (Andrena) maukensis Matsumura, 1911}

Тип ареала: сибиро-дальневосточный.

Материал: дорога, 3-12.VII, ЛС, СД - 2 фо; там же, ловушки Мерике, 7.VII, ЛС, СД - 1 q.

\section{Andrena (Euandrena) bicolor Fabricius, 1775}

Тип ареала: евро-сибирский.

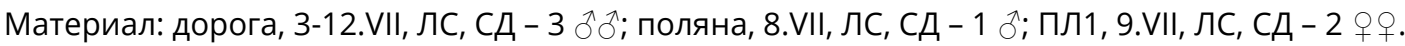

\section{Andrena (Euandrena) fulvida Schenck, 1853}

Тип ареала: трансевразиатский.

Материал: дорога, 3.VII, ЛС, СД - 5 фо; там же, ловушки Мерике, 7-8.VII, ЛС, СД - 2 фо; поляна, 7-13.VII, Приймук Д.С. -1 \%. 
Andrena (Hoplandrena) dentata Smith, 1879

Тип ареала: сибиро-дальневосточный.

Материал: дорога, 3.VII, ЛС, СД - 1 क; поляна, 7.VII, Дернова Е.В., Иванова А.С. - 2 q $;$; там же, ЛС, СД - 1 ; ПЛ1, 8.VII, Груздева Т.В. - 1 क.

Andrena (Melandrena) cineraria (Linnaeus, 1758)

Тип ареала: трансевразиатский.

Материал: поляна, 8.VII, Груздева Т.В. - 1 q.

Andrena (Melandrena) nitida (Müller, 1776)

Тип ареала: евро-сибирский.

Материал: поляна, 7.VII, Дернова Е.В. - 1 + .

Andrena (Micrandrena) minutuloides Perkins, 1914

Тип ареала: евро-сибирский.

Материал: поляна, 17.VIII, СД, ЯС - 1 я.

\section{Andrena (Micrandrena) subopaca Nylander, 1848}

Тип ареала: трансевразиатский.

Материал: дорога, 3-12.VII, ЛС, СД - 11 фо; там же, ловушки Мерике, 7-13.VII, ЛС, СД - 8 о; Пл2, ловушки Мерике, 12.VII, ЛС, СД - 1 ․

\section{Andrena (Oreomelissa) coitana (Kirby, 1802)}

Тип ареала: трансевразиатский.

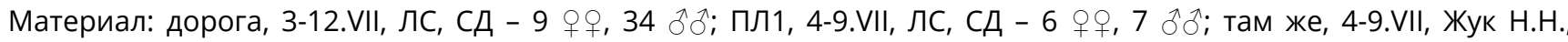

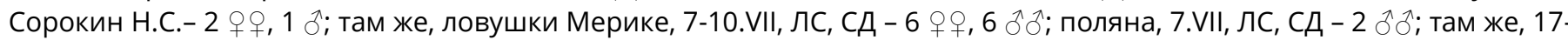
18.VIII, СД, ЯС - 7 о о; ПЛ2, ловушки Мерике, 8-9.VII, ЛС, СД - 1 q.

Andrena (Plastandrena) pilipes Fabricius, 1781

Тип ареала: трансевразиатский.

Материал: поляна, 18.VIII, СД, ЯС - 1 ․

\section{Семейство Halictidae}

Halictus (Protohalictus) hedini Blüthgen, 1934

Тип ареала: сибиро-дальневосточный.

Материал: ПЛ1, 8.VII, ЛС, СД - 2 фо; дорога, 12.VII, ЛС, СД - 1 ф; там же, 18.VIII, СД, ЯС - 18 фо ; поляна, 17-18.VIII, СД, ЯС - 8 우.

\section{Halictus (Seladonia) confusus Smith, 1853*}

Тип ареала: трансевразиатский.

Материал: поляна, 18.VIII, СД, ЯС - 1 ․

Halictus (Tytthalictus) maculatus Smith, 1848

Тип ареала: евро-сибирский.

Материал: ПЛ1, 13.VII, Лето Д.И. - 1 ф; дорога, 18.VIII, СД, ЯС - 3 $ぇ$.

\section{Lasioglossum (Lasioglossum) zonulum Smith, 1848*}

Тип ареала: голарктический.

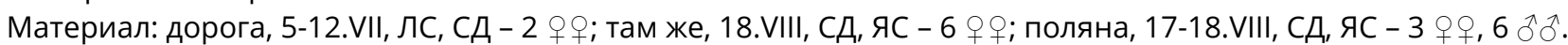

\section{Lasioglossum (Evylaeus) albipes (Fabricius, 1781)}

Тип ареала: трансевразиатский.

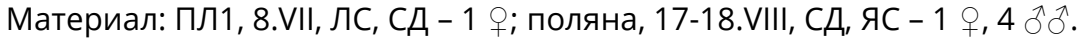

Lasioglossum (Evylaeus) amurense (Vachal, 1902)

Тип ареала: сибиро-дальневосточный.

Материал: дорога, 5-12.VII, ЛС, СД - 4 оя; там же, 18.VIII, СД, ЯС - 3 qо; ПЛ1, 8-9.VII, ЛС, СД - 3 о ; там же, ловушки Мерике, 7-13.VII, ЛС, СД - 6 ㅇ; пЛ2, ловушки Мерике, 12.VII, ЛС, СД - 1 ;; поляна, 17-18.VIII, СД, ЯС - 6 우, 3

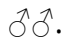


Lasioglossum (Evylaeus) calceatum (Scopoli, 1763)*

Тип ареала: трансевразиатский.

Материал: ПЛ1, 8.VII, ЛС, СД - 1 ․

Lasioglossum (Evylaeus) fratellum (Pérez, 1903)

Тип ареала: трансевразиатский.

Материал: дорога, 7.VII, ЛС, СД - 1 о; там же, ловушки Мерике, 13.VII, ЛС, СД - 1 ; ; ПЛ1, 7.VII, ЛС, СД - 1 \%; поляна, 17-18.VIII, СД, ЯС - 2 우, 1 万.

\section{Lasioglossum (Evylaeus) pauxillum (Schenck, 1853)}

Тип ареала: евро-сибирский.

Материал: поляна, 17-18.VIII, СД, ЯС - 4 우, 2 о수; дорога, 18.VIII, СД, ЯС - 2 ㅇ․

Lasioglossum (Evylaeus) rufitarse (Zetterstedt, 1838)

Тип ареала: трансевразиатский.

Материал: дорога, 3-12.VII, ЛС, СД - 7 क⿱宀; пЛ1, ловушки Мерике, 7.VII, ЛС, СД - 2 qक; поляна, 17-18.VIII, СД, ЯС - 4 우우, 1 ㅅ․

\section{Sphecodes ephippius (Linnaeus, 1767)}

Тип ареала: евро-сибирский.

Материал: дорога, 12.VII, ЛС, СД-1 9 .

\section{Sphecodes ferruginatus Hagens, 1882}

Тип ареала: трансевразиатский.

Материал: поляна, 17.VIII, СД, ЯС - 1 क.

\section{Sphecodes monilicornis (Kirby, 1802)*}

Тип ареала: трансевразиатский.

Материал: поляна, 18.VIII, СД, ЯС - 1 今.

\section{Sphecodes scabricollis Wesmael, 1835}

Тип ареала: трансевразиатский.

Материал: поляна, 12.VII, Лозовой П.А. - 1 ;; там же, 17.VIII, СД, ЯС - 1 q.

\section{Семейство Melittidae}

Macropis (Macropis) europaea Warncke, 1973*

Тип ареала: евро-сибирский.

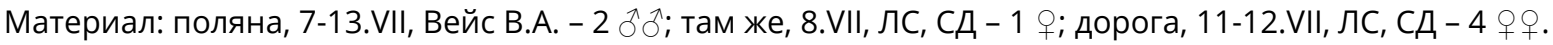

Macropis (Macropis) fulvipes (Fabricius, 1804)*

Тип ареала: евро-сибирский.

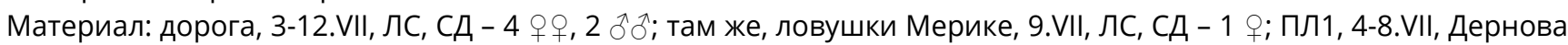
Е.В., Сорокин Н.С. - 2 우; поляна, 7-8.VII, ЛС, СД - 2 우, 6 숭.

\section{Семейство Megachilidae}

\section{Lithurgus (Lithurgus) cornutus (Fabricius, 1787)}

Тип ареала: голарктический.

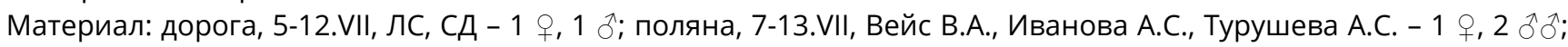

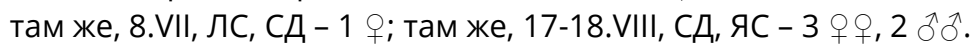

Hoplitis (Alcidamea) leucomelana (Kirby, 1802)

Тип ареала: трансевразиатский.

Материал: дорога, 8-12.VII, ЛС, СД - 2 ㅎํ.

Anthidium (Anthidium) septemspinosum Lepeletier de Saint-Fargeau, 1841

Тип ареала: трансевразиатский.

Материал: поляна, 18.VIII, СД, ЯС - 1 Аิ. 
Sidorov, D.A. Luzyanin, S.L. Fauna of bees (Hymenoptera, Apoidea).... Acta Biologica Sibirica, 2018, 4(1), 24-32

Coelioxys (Boreocoelioxys) alatus Föerster, 1853

Тип ареала: трансевразиатский.

Материал: дорога, 3.VII, ЛС, СД - 1 ф; поляна, 17-18.VIII, СД, яС - 3 фо .

Coelioxys (Boreocoelioxys) mandibularis Nylander, 1848

Тип ареала: трансевразиатский.

Материал: поляна, 7-13.VII, Краснокуцкая А.Д. - 1 о; там же, 17.VIII, СД, ЯС - 3 о о.

Coelioxys (Boreocoelioxys) rufescens Lepeletier de Saint-Fargeau et Audinet-Serville, 1825

Тип ареала: трансевразиатский.

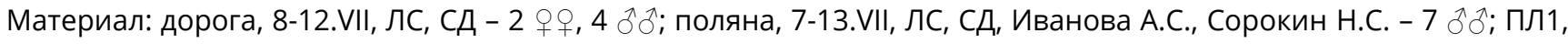
8.VII, ЛС, СД - 1 Ј.

\section{Coelioxys (Coelioxys) lanceolatus Nylander, 1852}

Тип ареала: трансевразиатский.

Материал: поляна, 7-13.VII, Вейс В.А., Иванова А.С. - 2 우.

\section{Megachile (Megachile) bombycina Radoszkowski, 1874}

Тип ареала: трансевразиатский.

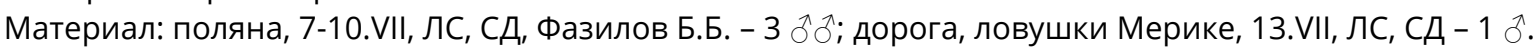

\section{Megachile (Megachile) genalis Morawitz, 1880}

Тип ареала: трансевразиатский.

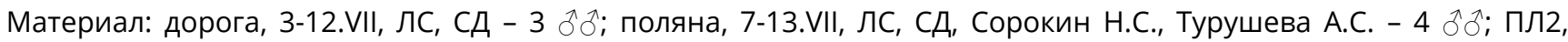

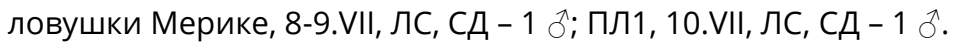

\section{Megachile (Megachile) Iapponica Thomson, 1872}

Тип ареала:голарктический.

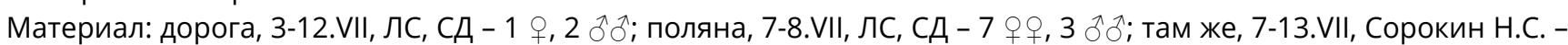

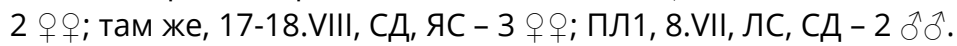

\section{Megachile (Megachile) ligniseca (Kirby, 1802)}

Тип ареала: трансевразиатский.

Материал: дорога, 5-12.VII, ЛС, СД - 2 qо; там же, 18.VIII, СД, ЯС - 5 qо; поляна, 7-13.VII, Вейс В.А., Дернова Е.В.,

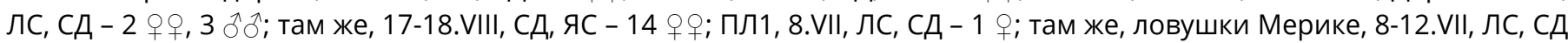

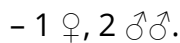

\section{Megachile (Xanthosarus) maackii Radoszkowski, 1874}

Тип ареала: трансевразиатский.

Материал: ПЛ1, 4.VII, ЛС, СД - 1 ; п поляна, 7-13.VII, Вейс В.А. - 1 о.

Megachile (Xanthosarus) willughbiella (Kirby, 1802)

Тип ареала: трансевразиатский.

Материал: поляна, 7-10.VII, Фазилов Б.Б. - 1 о.

\section{Семейство Apidae}

\section{Eucera (Eucera) longicornis (Linnaeus, 1758)}

Тип ареала: трансевразиатский.

Материал: поляна, 7.VII, Дернова Е.В. - 1 ภ.

\section{Anthophora (Clisodon) furcata (Panzer, 1798)}

Тип ареала: трансевразиатский.

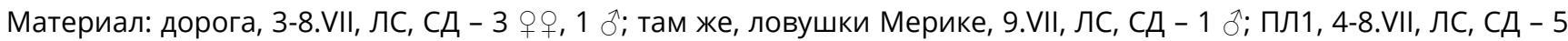

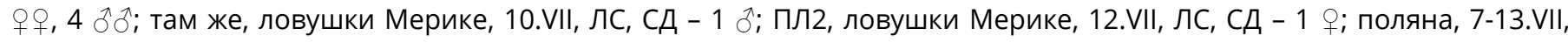
Дернова Е.В., Жук Н.Н, Иванова А.С., Лето Д.И., Сорокин Н.С. - 5 q, 1 §.

\section{Anthophora (Clisodon) terminalis Cresson, 1869}

Тип ареала: голарктический.

Материал: поляна, 7.VII, Иванова А.С. - 1 §̊; пЛ1, 8.VII, Макиенко Д.C. - 1 ф; дорога, 12.VII, ЛС, СД - 1 о; там же, ловушки Мерике, $10 . \mathrm{VII}$, ЛС, СД - 1 §. 
Bombus (Bombus) lucorum (Linnaeus, 1761)

Тип ареала: трансевразиатский.

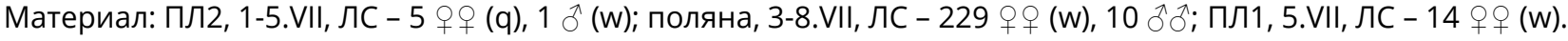

Bombus (Megabombus) consobrinus Dahlbom, 1832

Тип ареала: трансевразиатский.

Материал: поляна, 3-8.VII, ЛС - 6 q (q).

Bombus (Megabombus) hortorum (Linnaeus, 1761)

Тип ареала: трансевразиатский.

Материал: поляна, 3-4.VII, ЛС - 2 우 (q), 1 (w).

Bombus (Megabombus) saltuarius (Skorikov, 1931)

Тип ареала: трансевразиатский.

Материал: поляна, 4.VII, ЛС - 2 우 (w), 1 (q); ПЛ1, 5.VII, ЛС - 1 (w).

Bombus (Melanobombus) sichelii Radoszkowski, 1860

Тип ареала: трансевразиатский.

Материал: поляна, 3-8.VII, ЛС - 18 ㅇ (w).

Bombus (Psithyrus) barbutellus (Kirby, 1802)

Тип ареала: трансевразиатский.

Материал: поляна, 3-8.VII, ЛС - 6 우 (q).

Bombus (Psithyrus) bohemicus Seidl, 1837

Тип ареала: трансевразиатский.

Материал: поляна, 7.VII, ЛC - 2 ㅇ (q).

Bombus (Psithyrus) campestris (Panzer, 1801)

Тип ареала: трансевразиатский.

Материал: поляна, 3.VII, ЛС - 2 ㅇ (q); ПЛ1, 5.VII, ЛC - 1 (q).

Bombus (Psithyrus) rupestris (Fabricius, 1793)

Тип ареала: трансевразиатский.

Материал: поляна, 3.VII, ЛС - 2 ㅇ (q).

Bombus (Pyrobombus) hypnorum (Linnaeus, 1758)

Тип ареала: трансевразиатский.

Материал: поляна, 3.VII, ЛС - 1 † (q), 1 q (w).

Bombus (Pyrobombus) pratorum (Linnaeus, 1761)

Тип ареала: трансевразиатский.

Материал: поляна, 3-8.VII, ЛС - 15 qㅇ (w); ПЛ1, 8.VII, ЛС - 3 우 (w).

Bombus (Thoracobombus) pascuorum (Scopoli, 1763)

Тип ареала: трансевразиатский.

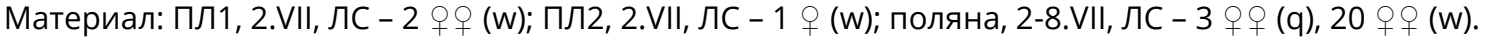

Bombus (Thoracobombus) schrencki Morawitz, 1881

Тип ареала: трансевразиатский.

Материал: ПЛ2, 2.VII, ЛС - 1 ф (w); поляна, 4-8.VII, ЛС - 1 † (q), 1 ф (w).

Фауна пчел липового острова имеет структуру, характерную таёжным лесам Западной Сибири (Panfilov, 1968). По числу видов наиболее представлено семейство Арidae (18 видов), немного ниже видовое богатство семейств Halictidae (16) Megachilidae (15) и Andrenidae (14). К семейству Colletidae принадлежит 9 видов, Меlittidaе - только два. Число родов максимально в семействе Megachilidae - 6. Halictidae и Аріdaе представлены тремя родами, Colletidae, Andrenidae и Melittidae - всего одним. Наибольшим числом видов представлены роды Вотbus (15), Andrena (14), Hylaeus (9) и Lasioglossum (8), минимальное видовое обилие имеют Lithurgus, Hoplitis и Anthidium - 1 вид.

По численному обилию, при исключении из рассмотрения шмелей, резко преобладают представители семейства Colletidae (род Hylaeus) - 41,3 \% от общего числа особей, несколько менее многочисленны виды 
Sidorov, D.A. Luzyanin, S.L. Fauna of bees (Hymenoptera, Apoidea).... Acta Biologica Sibirica, 2018, 4(1), 24-32

семейства Andrenidae (род Andrena) - почти 26 \%. Наибольшее численное обилие характерно видам Нylaеus rinki, Andrena fucata, Hylaeus cardioscapus, Andrena coitana и Hylaeus confusus.

Среди 15 видов шмелей, обнаруженных в Липовом острове, наиболее многочисленными являются 3 широко распространённых на юге Сибири вида: эвритопные Bombus lucorum, B. pascuorum и луговой B. sichelii. Суммарное численное обилие их составляет более 71 \%. К типично лесным видам шмелей можно отнести $B$. consobrinus, $B$. schrencki, B. modestus и B. saltuarius. Таким образом, Липовый остров заселён наиболее массовыми и экологически пластичными видами шмелей. Тем не менее, нужно отметить, что два вида (B. modestus и B. sporadicus) занесены в Красную книгу Кемеровской области (Skalon et al., 2012).

Видовой состав шмелей практически не меняется в течение всего летнего сезона, поэтому в дальнейшем обсуждении фенологической динамики фауны эта группа эусоциальных пчел не учитывается. В начале лета (22-25 мая) полностью отсутствуют виды родов Hylaeus, Sphecodes, Macropis, Eucera, Anthophora и все виды из семейства Megachilidae, кроме Osmia bicolor. В это время преобладают виды рода Lasioglossum - 6 видов из 13 и около 54 \% от числа особей пчел, собранных в это время. В середине лета (1-13 июля) видовое богатство пчел достигает максимума - 47 видов, из которых 38 достигают в середине лета наибольшего численного обилия, а 22 вида отмечены только в этот фенологический период. Наиболее обильны виды рода Нylaeus - встречаются все 9 видов, численное обилие которых достигает почти 45 \% от общего числа особей пчел, а также Andrena - 10 видов, около 31 \% особей. Lasioglossum практически не изменяют видового и численного обилия по сравнению с началом лета, но по относительным показателям отходят на второй план. В конце лета (17-18 августа) исчезают представители родов Andrena (кроме сокращающего численное обилие A. coitana и представленных единственными экземплярами $A$. minutuloides и A. pilipes), Macropis, Hoplitis, Osmia, Eucera, Anthophora, но возрастает число особей у видов из родов Halictus и Lasioglossum, а также их клептопаразитов Sphecodes. Видовое и численное обилие представителей родов Hylaeus, а также Megachile и их клептопаразитов Coelioxys существенно снижается.

Большинство обнаруженных видов пчел имеет обширные ареалы - трансевразиатские (48 видов, почти $65 \%$ от их общего числа) и голарктические (6 видов, около 8 \%). Евро-сибирский тип ареала имеют 15 видов (около $20 \%$ ), сибиро-дальневосточный - 5 видов (около 7 \%). По численному обилию (без учёта шмелей) также преобладают трансевразиатские и евро-сибирские виды (62,5 \% и 18,4 \% от общего числа особей соответственно), однако сибиродальневосточные виды имеют существенно большее численное обилие (12,1\%), чем голарктические (около 7 \%). Виды с узкими ареалами, локальные эндемики или новые для науки виды в фауне Липового острова выявлены не были. Интересно, что длинноязычковые пчелы (Megachilidae и Apidae) имеют трансевразиатские или голарктические ареалы (кроме единственного евро-сибирского Osmia bicolor), а сибиро-дальневосточные виды довольно равномерно представлены среди короткоязычковых пчел (Hylaeus nigrocuneatus, Colletidae; Andrena dentata и A. maukensis, Andrenidae; Halictus hedini и Lasioglossum amurense, Halictidae).

\section{Благодарности}

Авторы благодарят научного сотрудника Зоологического института РАН (г. Санкт-Петербург) Ю.В. Астафурову за определение пчел семейства Halictidae и доцента Новосибирского государственного университета А.М. Бывальцева за определение пчел семейства Megachilidae. Также выражаем признательность директору и сотруднику Кузедеевского территориального отдела Лесного комплекса Кемеровской области В.Н. Егорову и В.В. Абрамову за помощь в организации экспедиции.

Исследование выполнено при финансовой поддержке РФФИ в рамках научного проекта № 16-34-00209 мол_а.

\section{References}

Amelin, I.I. \& Blyakharchuk, T.A. (2016). Distribution of Siberian linden (Tilia sibirica Bayer) in Kemerovo oblast. Vestnik Tomskogo gosudarstvennogo universiteta. Biologiya, 2(34): 30-52 (in Russian). doi:10.17223/19988591/34/3

Antropov, A.V., Astafurova, Yu.V., Belokobylskij, S.A., Byvaltsev, A.M., Danilov, Yu.N., Dubovikoff, D.A., Fadeev, K.I., Fateryga, A.V., Kurzenko, N.V., Lelej, A.S., Levchenko, T.V., Loktionov, V.M., Mokrousov, M.V., Nemkov, P.G., Proshchalykin, M.Yu., Rosa, P., Sidorov, D.A., Sundukov, Yu.N., Yusupov, Z.M. \& Zaytseva, L.A. (2017). Annotated catalogue of Hymenoptera of Russia. Volume I. Symphyta and Apocrita: Aculeata. Proceedings of the Zoological Institute RAS, 6. (Suppl.). 1-475.

Astafurova, Yu.V. \& Proshchalykin, M.Yu. (2015). Bees of the genus Sphecodes Latreille 1804 of Siberia, with a key to species (Hymenoptera: Apoidea: Halictidae). Zootaxa, 4052(1), 65-95.

Astafurova, Yu.V. \& Proshchalykin, M.Yu. (2017). Additional data on the short-tongued bee fauna (Hymenoptera, Apoidea: Andrenidae, Halictidae, Melittidae) of Russia. Proceedings of the Russian Entomological Society, 88(2): 81-85.

Gorodkov, K.B. (1984). Ranges types of insects of tundra and firest zones of European Part of U.S.S.R. Provisional atlas of the Insects of the European Part of U.S.S.R. Leningrad: Nauka (in Russian).

Krapivkina, E.D. (2009). Nemoral relicts in the flora of chernevaya taiga of Gornaya Shoria. Novosibirsk: Siberian Branch of the Russian Academy of Sciences (in Russian).

Michener, C.D. (2007). The Bees of the World [2nd Edition]. Baltimore: Johns Hopkins University Press. 
Sidorov, D.A. Luzyanin, S.L. Fauna of bees (Hymenoptera, Apoidea).... Acta Biologica Sibirica, 2018, 4(1), 24-32

Panfilov, D. V. (1968) Obshchiy obzor naseleniya pchelinykh Yevrazii. Sbornik trudov Zoologicheskogo muzeya MGU, 11: 18-35 (in Russian).

Proshchalykin, M.Yu., Astafurova, Yu.V. \& Shlyahtyonok, A.S. (2016). A review of the genus Melitturga Latreille, 1809 (Hymenoptera, Apoidea, Andrenidae) of the fauna of Russia and adjacent territories. Euroasian entomological journal, 15(6), 566-571. (In Russian).

Proshchalykin, M.Yu. \& Dathe, H.H. (2016). Additional records of the genus Hylaeus Fabricius, 1793 (Hymenoptera: Apoidea: Colletidae) from Siberia, with description of a new species. Zootaxa, 4105(4), 301-320. https://doi.org/10.11646/zootaxa.4105.4.1

Proshchalykin, M.Yu. \& Kuhlmann, M. (2015). Additional records of the genus Colletes Latreille (Hymenoptera: Apoidea: Colletidae) from Siberia, with a checklist of Russian species. Zootaxa, 3949(3), 323-344. https://doi.org/10.11646/zootaxa.3949.3.2

Proshchalykin, M.Yu. \& Lelej, A.S. (2014). Review of the genus Ammobatoides Radoszkowski, 1867 (Hymenoptera: Apidae, Nomadinae) from Russia and neighbouring countries. Zootaxa, 3852(4), 445-460. https://doi.org/10.11646/zootaxa.3852.4.3

Sidorov, D.A., Luzyanin, S.L. \& Yakovleva, S.N. (2016). First records of bees (Hymenoptera, Apiformes) in the relict lime forest of the Mountain Shoria. Sovremennyey Problemy Nauki i Obrazovaniya, 6 (in Russian). http://www.scienceeducation.ru/article/view?id=25798

Sidorov, D.A. \& Proshchalykin, M.Yu (2017). New records of bees of the genus Andrena Fabricius (Hymenoptera, Apoidea: Andrenidae) from the southern part of East Siberia, Russia. Euroasian entomological journal, 16(2): 173-179 (In Russian). http://www.eco.nsc.ru/EEJ_contents/16/201716210.pdf

Sidorov, D.A., Proshchalykin, M.Yu., Konusova, O.L., Belova, K.A., Byvaltsev, A.M. (2017). Contribution to the fauna of the genus Andrena Fabricius (Hymenoptera: Apoidea: Andrenidae) of Western Siberia. Proceedings of the Russian Entomological Society, 88(2): 66-80.

Skalon, N.V., Gagina, T.N., Yeremeyeva, N.I., Yefimov, D.A., Il'yashenko, V.B., Luzyanin, S.L., Luchnikova, E.M., Onishchenko, S.S., Polevod, V.A., Sushchov, D.V., Bibik, E.V., Blinova, S.V., Dronzikova, M.V., Zinchenko, V.K., Kovalevskiy, A.V., Kosterin, O.E., Sidorov, D.A., Skalon, O.N., Skalon, T.N., Teplova, N.S., Kharitonov, A.Yu. (2017). Krasnaya kniga Kemerovskoy oblasti: T. 2. Redkiye i nakhodyashchiyesya pod ugrozoy ischeznoveniya vidy zhivotnykh. [2-ye izdye]. Kemerovo: Aziya print (in Russian).

\section{Citation:}

Sidorov, D.A. Luzyanin, S.L. (2018). Fauna of bees (Hymenoptera, Apoidea: Apiformes) of the relict lime forest of the mountain Shoria. Acta Biologica Sibirica, 4 (1), 24-32.

Submitted: 28.12.2017. Accepted: 15.02.2018

crossref http://dx.doi.org/10.14258/abs.v4i1.3913

(C) 2018 by the authors. Submitted for possible open access publication under the terms and conditions of the Creative Commons Attribution (CC BY) license (http://creativecommons.org/licenses/by/4.0/). 